\title{
Ki-67, p53, FAS, Erb-B2, E-cadherin and $\beta$-catenin Immunoexpression in Oral Squamous Cells Carcinomas and in its Corresponding Early Local Recurrences
}

\section{Francisco Carlos Amanajás de Aguiar Júnior ${ }^{1 *}$, Oslei Paes de Almeida² and Luiz Paulo Kowalski}

${ }^{1}$ Academic Center of Vitoria, Federal University of Pernambuco, Rua Alto do Reservatório s/n, Bela Vista, CEP: 55608-680, Vitória de Santo Antão/PE, Brazil ${ }^{2}$ Department of Oral Pathology and Semiology, School of Dentistry of Piracicaba, University of Campinas, Av. Limeira, 901, Cx. Postal 52, CEP: 13414-018, Piracicaba/ $S P$, Brazil

${ }^{3}$ Department of Head and Neck Surgery and Otorhinolaryngology, AC Camargo Hospital, Rua Prof. Antônio Prudente, 211, Liberdade, CEP: 01509-010- São Paulo/SP, Brazil

\begin{abstract}
Local recurrence is one of the main causes of treatment failure in patients with Oral Cell Squamous Carcinoma (OSCC) and has a significant negative impact on prognosis. There are few studies considering the biological characteristics of Early Local Recurrence (ELR), particularly comparing to the primary tumor. In this study, we compared the immunoexpression of p53, FAS (Fatty acid synthase), Erb-B2, $\beta$-catenin and E-cadherin and the proliferation marker Ki-67 in 17 Primary Tumors (PT) and its respective ERLs. The kappa index was used for statistical analysis. All markers used were expressed similarly in both primary and early recurrent tumor, considering the mean percentage or positive cases. No difference was observed between the expression of p53 (kappa- = 0.881 ), FAS (kappa- $=0.673$ ), Erb-B2 (membrane (M) kappa $=0.337$ and cytoplasmic $(\mathrm{C}) \mathrm{kappa}=0.767$ ), $\beta$-catenin $(\mathrm{M}:$ kappa $=0.337$ and $\mathrm{C}: \mathrm{kappa}=0.767)$ and $\mathrm{E}$-cadherin $(\mathrm{M}: \mathrm{kappa}=0.337$ and $\mathrm{C}: \mathrm{kappa}=0.767)$ in the PTS and in its corresponding ERLs. However, the proliferation marker Ki-67 showed a low kappa index (kappa: 0.179). This different proliferation rate between PTS and in its corresponding ERLs could be better investigated and further be considered in the clinical management of ERLs.
\end{abstract}

Keywords: Oral carcinoma; Treatment failure; Primary tumor; Biomarkers

\section{Introduction}

Oral Squamous Cell Carcinoma (OSCC) is considered the result of a multi-step process, which involves a number of aberrant genetic events. Multiple oncogenes, regulatory factors, and tumor suppressor genes play a role in its development and progression $[1,2]$.

In clinical practice, the planning of treatment and the prediction of prognosis for patients with OSCC are mainly based on the TNM classification and some histopathological criteria [3]. However, the clinical outcome does not always follow the expectation of those parameters, since they do not provide any information regarding the biological characteristics of the tumor.

Local recurrence appears as one of the main causes for treatment failure and has a significant negative impact on the prognosis of patients of OSCC. Despite these observations, many studies evaluate biomarkers that could identify patients at highest risk of local recurrence $[4,5]$. Therefore, these markers are not commonly reassessed in the local recurrence, especially in those cases in which the recurrence occurs precociously.

The aim this study was compare the immunohistochemical expression of six biomarkers: Ki-67, p53, bcl-2, FAS (Fatty acid synthase), Erb-B2, $\beta$-catenin and E-cadherin in OSCC primary tumor (PT) and their respective early local recurrences (ERL).

\section{Material and Methods}

The study was performed in seventeen patients diagnosed and treated at the Department of Head and Neck Surgery and Otorhinolaryngology, A.C. Camargo Cancer Hospital, São Paulo, Brazil, evaluated retrospectively for early local recurrence of oral squamous cell carcinoma (OSCC). The inclusion criteria for all cases were: all the patients had biopsy proven OSCC, not received prior therapy to the primary site, had been submitted to surgical treatment at A.C. Camargo Hospital. The exclusion criteria were the presence of OSCC in the margins, or even close $(<5 \mathrm{~mm})$ of the surgical resection and less than 2 years follow-up after the definitive treatment. Clinical information, including age, gender, smoking and alcohol intake history, TNM classification, and location, treatment and outcome data was obtained from patients' files. The characteristics of the all patients selected for this study are summarized in Table 1. This study was carried out with approval of the Human Research Ethics Committee of the A.C. Camargo Hospital. The respective paraffin-embedded block of the primary tumor and its local recurrence was taken from the pathological archives for analysis.

The paraffin embedded tissue samples were cut $(3 \mu \mathrm{m})$ and mounted on silane-coated glass slides for Hematoxylin and Eosin (H\&E) staining and immunohistochemistry. Briefly, the sections were deparaffinized, rehydrated in graded ethanol solutions. Endogenous peroxidase activity was blocked by using $3 \% \mathrm{H}_{2} \mathrm{O}_{2}$ for 25 min at room temperature. Microwave (Panasonic, $1380 \mathrm{~W}$ ) antigen retrieval

*Corresponding author: Francisco Carlos Amanajás de Aguiar Júnior, Academic Center of Vitoria, Federal University of Pernambuco, Rua Alto do Reservatório s/n, Bela Vista, CEP: 55608-680, Vitória de Santo Antão/PE, Brazil, Tel: + 55-81-35233351; E-mail: famanajas@yahoo.com.br

Received May 14, 2012; Accepted May 19, 2012; Published May 21, 2012

Citation: de Aguiar Júnior FCA, de Almeida OP, Kowalski LP (2012) Ki-67, p53, FAS, Erb-B2, E-cadherin and $\beta$-catenin Immunoexpression in Oral Squamous Cells Carcinomas and in its Corresponding Early Local Recurrences. J Cancer Sci Ther 4: 127-130. doi:10.4172/1948-5956.1000126

Copyright: (C) 2012 de Aguiar Júnior FCA, et al. This is an open-access article distributed under the terms of the Creative Commons Attribution License, which permits unrestricted use, distribution, and reproduction in any medium, provided the original author and source are credited. 
Citation: de Aguiar Júnior FCA, de Almeida OP, Kowalski LP (2012) Ki-67, p53, FAS, Erb-B2, E-cadherin and $\beta$-catenin Immunoexpression in Oral Squamous Cells Carcinomas and in its Corresponding Early Local Recurrences. J Cancer Sci Ther 4: 127-130. doi:10.4172/19485956.1000126

consisted of two periods of 12 minutes in $10 \mathrm{mM}$ citric acid solution ( $\mathrm{pH}$ 6.0) followed by a washing step with Phosphate-Buffered Saline (PBS). The incubations with the primary antibodies diluted in PBS were made overnight at $4^{\circ} \mathrm{C}$ : anti-FAS ( Transduction Laboratories, Lexington, KY)1:3000, anti-Erb-B2 (Dako, Carpinteria, CA) 1:200, anti-Ki-67 MIB 1 (Dako, Carpinteria, CA) 1:100, E-cadherin (Novocastra, Newcastle, UK) 1:200, $\beta$-catenin (Novocastra, Newcastle, UK) 1:200, p53 (Dako, Carpinteria, CA) 1:200. Sections were washed again and incubated with biotinylated secondary antibodies for 30 minutes followed by the streptavidin-biotin-peroxidase (Strep ABC complex/HRP Duet kit, Dako) for 30 minutes at room temperature. Reactions were developed with a solution containing $0.6 \mathrm{mg} / \mathrm{ml}$ of 3 '3- diaminobenzidine tetrahydrochloride (DAB, Sigma) and $0.01 \% \mathrm{H}_{2} \mathrm{O}_{2}$ and counter stained with Carazzi's haematoxylin, mounted, and analyzed under an optical microscope. Positive and negative controls were included in all reactions. Two observers (FCAA and OPA) independently evaluated and interpreted the results of immunostaining without knowledge of clinical data of patients. The percentage of Ki-67 positive nuclei was calculated with the aid of an image computer analyzer (Kontron 400, Carl Zeiss, Germany) by counting a total of 1000 cancer cells in each sample and assessing the percentage of labeled cells. The percentage of positive cells in the FAS, p53, Erb-B2, E-cadherin and $\beta$-catenin immunostaining was semiquantitavely evaluated into one of the following groups: $<5 \%$ were defined as negative (or lack of expression), and $>5 \%$ were defined as positive.

The kappa index was used in the statistical analysis for the correlation of the markers expressed on the PTs and its respective ELRs. Values of kappa range from -1 to +1 . A value $<0.20$ indicates weak correlation, 0.21 to 0.40 fair, 0.41 to 0.60 moderate, 0.61 to 0.80 good, and 0.81 to 1 excellent correlation [6].

\section{Results}

The studied population consisted of 17 patients, from which 16
(94.11\%) were male and 1 (5.89\%) female, with mean age of 56.47 years, ranging from 40 to 73 years. The history of smoking and alcohol consumption was reported in 16 (94.11\%) and 15 (88.23\%) patients respectively. Tumors were sited at tongue in 14 cases $(82.35 \%)$ and in 3 (17.65\%) at retromolar area. The Clinical Stage (CS) of the patients were CS I, 3 cases (17.64\%); CS II, 2 cases (11.76\%); CS III, 8 cases $(47.05 \%)$ and CS IVa, 4 cases (23.55\%). Among all cases, 11 (64.70\%) patients underwent surgical resection of the primary tumor only and $6(35.30 \%)$ underwent surgical resection and radiotherapy. The recurrence time after the first treatment was from 1.70 to 7.33 months, with the mean of 4.98 months.

Immunohistochemical analysis of Ki-67, p53, FAS, Erb-B2, E-cadherin and $\beta$-catenin in both PT and ERL showed similar protein expression, and the results are summarized in the Table 2 and 3.

Nuclear staining of Ki-67, for statistical analysis, a threshold value of $17.5 \%$ (median) Ki-67-positive tumor cells separated tumors with a high proliferation rate $(\mathrm{Ki}-67 \geq 17.5 \%)$ from tumors with a low proliferation rate $(\mathrm{Ki}-67<17.5 \%)$. In 9 PTs, which showed a low proliferation rate, $4(44.44 \%)$ showed a higher proliferation in their respective ERL. In $8 \mathrm{PT}$, which showed a high proliferation rate in $\mathrm{PT}$, $3(37.5 \%)$ showed a lower proliferation in their respective ERL (kappa $=0.179)$.

Immunohistochemically detectable p53 protein accumulation was observed in 9 (52.94\%) PTs and 10 (58.83\%) ELRs. All reactions with a distinct nuclear staining were considered positive, regardless their intensities.

The FAS positivity was cytoplasmic and this positivity was more intense in well differentiated areas in the OSCC (Figure 1). The cytoplasmatic membrane of adipocytes stained strongly with FAS antibody and served as an additional positive control. FAS positivity showed no difference between the groups.

\begin{tabular}{|c|c|c|c|c|c|c|c|c|}
\hline Case & Age & Gender & $\begin{array}{c}\text { Smoking } \\
\text { Habit }\end{array}$ & $\begin{array}{c}\text { Alcohol } \\
\text { Use }\end{array}$ & Localization & TNM & Treatment & Disease-free survival $^{*}$ \\
\hline 1 & 42 & Male & Yes & Yes & Tongue & 310 & Sur/Rad & 6.18 \\
\hline 2 & 51 & Male & Yes & Yes & Tongue & 310 & Sur/Rad & 5.65 \\
\hline 3 & 51 & Male & Yes & No & Retromolar & 210 & Surgery & 1.93 \\
\hline 4 & 73 & Female & Yes & Yes & Tongue & 200 & Surgery & 5.71 \\
\hline 5 & 72 & Male & No & Yes & Tongue & 200 & Surgery & 5.98 \\
\hline 6 & 49 & Male & Yes & Yes & Tongue & 310 & Surgery & 5.75 \\
\hline 7 & 57 & Male & Yes & Yes & Tongue & 400 & Surgery & 3.64 \\
\hline 8 & 69 & Male & Yes & No & Tongue & 100 & Surgery & 4.24 \\
\hline 10 & 58 & Male & Yes & Yes & Tongue & 310 & Sur/Rad & 6.90 \\
\hline 11 & 49 & Male & Yes & Yes & Tongue & 100 & Surgery & 1.70 \\
\hline 12 & 65 & Male & Yes & Yes & Tongue & 100 & Surgery & 5.95 \\
\hline 13 & 70 & Male & Yes & Yes & Tongue & 300 & Surgery & 3.78 \\
\hline 14 & 60 & Male & Yes & Yes & Retromolar & 400 & Surgery & 4.79 \\
\hline 15 & 40 & Male & Yes & Yes & Retromolar & $42 a 0$ & Sur/Rad & 3.64 \\
\hline 16 & 45 & Male & Yes & Yes & Tongue & 210 & Surgery & 4.86 \\
\hline 17 & 53 & Male & Yes & Yes & Tongue & 300 & Sur/Rad & 7.33 \\
\hline
\end{tabular}

*Time in Months

Table 1: Distribution of 17 cases of early recurrence of oral squamous cell carcinomas according to demographic, lifestyle and clinical variables. 
Citation: de Aguiar Júnior FCA, de Almeida OP, Kowalski LP (2012) Ki-67, p53, FAS, Erb-B2, E-cadherin and $\beta$-catenin Immunoexpression in Oral Squamous Cells Carcinomas and in its Corresponding Early Local Recurrences. J Cancer Sci Ther 4: 127-130. doi:10.4172/19485956.1000126

A membrane and granular cytoplasm of Erb-B2, $\beta$-catenin (Figure 1) and E-cadherin staining were identified and considered in our study. A membrane staining was mainly found in well-differentiated areas, noticeably in areas showing formation of keratin pearls, whereas cytoplasmic staining was found mainly in undifferentiated cells. $\beta$-catenin is also known to be found in the nucleus under certain conditions. However, we did not detect this specific accumulation, possibly as a result of the specimen preparation methods used.

No significant changes in the immunoexpression of p53, FAS, Erb-B2, E-cadherin and $\beta$-catenin were observed in PTs and their respective ELR when the kappa index was used (Table 3).

\section{Discussion}

An accumulation of genetic alterations is the basis for the OSCC progression, referred as multi-step carcinogenesis [7]. Gene function can be altered in different ways: aberrant function of genes that positively or negatively regulate aspects of proliferation, apoptosis, genome stability, angiogenesis, invasion and metastasis [8].

It is a widely-known experience that after adequate treatment of OSCC, there is still a high risk of reappearance of another tumor in the same anatomical area. Local recurrence appears as one of the main causes for treatment failure after definitive therapy [9-11] and occasionally this recurrence may occur precociously.

Most cases of recurrence can be explained by the regrowth of incompletely resected OSCC [12]. However, when the histopathological assessment of surgical margins has shown that the resection of the tumor had been efficient, it is a clinical challenge to determine the possible causes for early local recurrence development. Since this type of lesion can be the result of remaining tumor cells, the PTs and ERLs must share the same profile of tumor markers, given the fact that,

\begin{tabular}{|c|c|c|c|}
\hline Variable & Category & PT n (\%) & ELR n (\%) \\
\hline \multirow[t]{2}{*}{ Ki-67 } & $\leq 17.5 \%$ & 9 (52.94) & $8(47.06)$ \\
\hline & $>17.5 \%$ & $8(47.06)$ & $9(52.94)$ \\
\hline \multirow[t]{2}{*}{ p53 } & + & $9(52.94)$ & $10(58.83)$ \\
\hline & - & $8(47.06)$ & $7(41.17)$ \\
\hline \multirow[t]{2}{*}{ FAS } & + & $13(70.47)$ & $13(70.47)$ \\
\hline & - & $4(23.53)$ & $4(23.53)$ \\
\hline \multirow[t]{2}{*}{ Erb-B2 Membrane } & + & $12(70.58)$ & $11(64.71)$ \\
\hline & - & $5(29.42)$ & $6(35.29)$ \\
\hline \multirow[t]{2}{*}{ Erb-B2 Cytoplasm } & + & $7(41.17)$ & $9(52.94)$ \\
\hline & - & $10(58.83)$ & $8(47.06)$ \\
\hline \multirow[t]{2}{*}{ E-cad Membrane } & + & $14(82.35)$ & $15(88.23)$ \\
\hline & - & $3(17.65)$ & $2(11.74)$ \\
\hline \multirow[t]{2}{*}{ E-cad Cytoplasm } & + & $6(35.29)$ & $4(23.53)$ \\
\hline & - & $11(64.71)$ & $13(70.47)$ \\
\hline \multirow[t]{2}{*}{$\beta$-Cat Membrane } & + & $13(70.47)$ & 15 (88.23) \\
\hline & - & $4(23.53)$ & $2(11.74)$ \\
\hline \multirow[t]{2}{*}{$\beta$-Cat Cytoplasm } & + & $4(23.53)$ & $4(23.53)$ \\
\hline & - & $13(70.47)$ & $13(70.47)$ \\
\hline
\end{tabular}

Table 2: Immunoexpression of Ki-67, p53, FAS, Erb-B2, E-cadherin and $\beta$-catenin in 17 Primary tumor (PT) of oral squamous cell carcinoma (OSCC) and 17 early local recurrent (ELR) OSCC.

\begin{tabular}{|c|c|c|c|}
\hline PT & & ERL & kappa \\
\hline Ki-67 & $\leq 17.5 \%$ & $>17.5 \%$ & \\
\hline$\leq 17.5 \%$ & 5 & 4 & 0.179 \\
\hline$>17.5 \%$ & 3 & 5 & \\
\hline p53 & - & + & \\
\hline- & 7 & 1 & 0.881 \\
\hline+ & 0 & 9 & \\
\hline FAS & - & + & \\
\hline- & 3 & 1 & 0.673 \\
\hline+ & 1 & 12 & \\
\hline Erb-B2 Membrane & - & + & \\
\hline- & 3 & 2 & 0.337 \\
\hline+ & 3 & 9 & \\
\hline Erb-B2 Cytoplasmic & - & + & \\
\hline- & 8 & 2 & 0.767 \\
\hline+ & 0 & 7 & \\
\hline E-cad Membrane & - & + & \\
\hline- & 0 & 3 & 0.767 \\
\hline+ & 2 & 12 & \\
\hline E-cad Cytoplasmic & - & + & \\
\hline- & 10 & 1 & 0.442 \\
\hline+ & 3 & 3 & \\
\hline$\beta$-Cat Membrane & - & + & \\
\hline- & 2 & 2 & 0.604 \\
\hline+ & 0 & 13 & \\
\hline$\beta$-Cat Cytoplasmic & - & + & \\
\hline- & 11 & 2 & 0.326 \\
\hline+ & 2 & 2 & \\
\hline
\end{tabular}

Table 3: Imunoexpression of Ki-67, p53, FAS, Erb-B2, E-cadherin and $\beta$-catenin in the primary tumor (PT) and their respective early local recurrent (ELR).

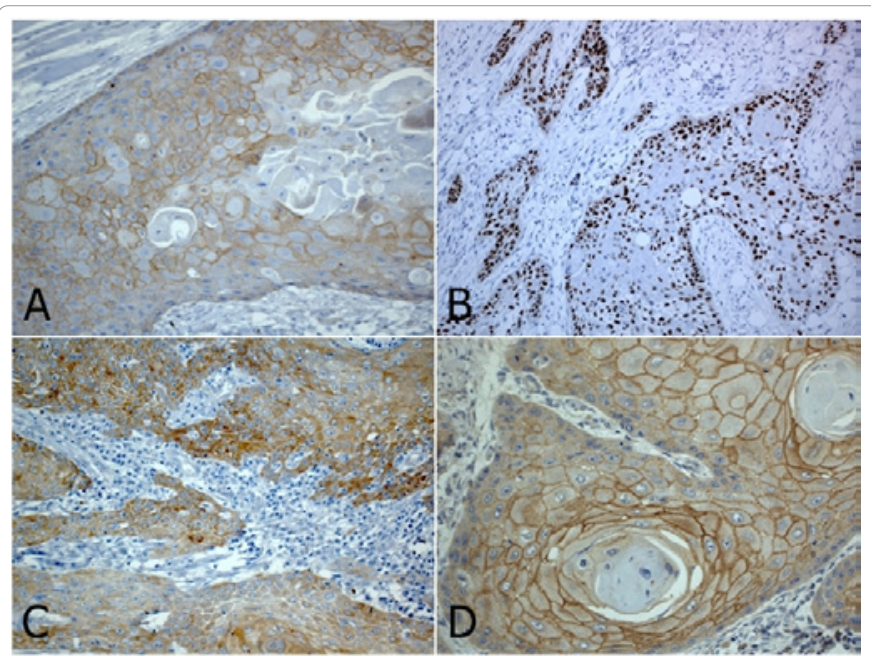

Figure 1: Immunohistochemical staining of $\beta$-Catenin, Ki-67, FAS and ErB-b2 expression in OSCC: (A) $\beta$-catenin (original magnification 400x), (B) Ki-67 (original magnification 200x), (C) FAS (original magnification 200x) and (D) ErB-b2 (original magnification 400x).

by definition, the recurrence is regarded as the return of the same primitive tumor [7].

Several works have focused on defining biomarkers, from which, the tumor suppressor gene, p53 is the most frequently studied. Alterations of the 533 gene are the most frequently documented genetic abnormalities in OSCC [1]. Our data are in accordance with those described in the literature, in which p53 expression ranges from $40 \%$ 
Citation: de Aguiar Júnior FCA, de Almeida OP, Kowalski LP (2012) Ki-67, p53, FAS, Erb-B2, E-cadherin and $\beta$-catenin Immunoexpression in Oral Squamous Cells Carcinomas and in its Corresponding Early Local Recurrences. J Cancer Sci Ther 4: 127-130. doi:10.4172/19485956.1000126

to $60 \%$ of head neck cancers [13]. Overexpression of Erb-B2, which is a $185-\mathrm{KD}$ transmembrane protein with tyrosine kinase activity, seen to be involved in OSCC progression [14,15]. We observed a $70.58 \%$ membrane and $41.17 \%$ cytoplasmic staining of ERB-B2 in PT, the membrane staining was similar to the one found by Silva et al. [14] however, the cytoplasmic staining was fewer than one reported in that study, probably due to the different criterion for positiveness used. The E-cadherin and $\beta$-catenin complex plays a critical role in the epithelial cell-cell contact and maintenance of tissues. Several studies also suggest that the expressions of these molecules are also altered in OSCC $[16,17]$. We did not found dissimilarities in these proteins expression in the PTs and in ELR, although altered expression of these molecules is involved in cancer cell locomotion, proteolisys, survival and proliferation in close and distant sites [16,17]. Fatty acid synthase (FAS) is a complex of seven enzymes required for endogenous fatty acid synthesis, and its increased expression has been described in several human tumors [1821]. FAS changed expression seems to be uncommon in OSCC, since only $2(11.74 \%)$ cases showed discordance in PTs and ERL.

Proliferation rate is also recognized as a potential prognostic factor in the OSCC. The Ki-67 antibody, has been used widely for estimation of the growth fraction of clinical samples of human neoplasms $[22,23]$. In our study, ELR changed the proliferation rate when compared to the OSCC PTs. Different treatment approach, especially the postoperative radiotherapy used in $6(35.30 \%)$ patients, could be involved. Within a given tumor, subpopulations of cells exist and differ in growth rates and other biologic properties [24]. Also, the postoperative radiotherapy should be acted causing an additional clone selection. In $44.44 \%$ of the OSCC analyzed, a change of their proliferation rate from low to high in their respective ERL was observed. This fact should be given a thorough investigation, inasmuch as it may be useful to guide ELRs treatment decision in the current clinical practice.

The present report showed a significant correlation of p53, FAS, Erb-B2, $\beta$-catenin and E-cadherin immunoexpression in cases of oral squamous cell carcinoma primary tumors and its early local recurrences samples. However, some discordance between the tumors was observed.

\section{Acknowledgments}

We thank Ana Cristina A. Godoy for the assistance with the immunohistochemical reactions and Inês Nishimoto for statistical analysis.

\section{References}

1. Scully C, Field JK, Tanzawa H (2000) Genetic aberrations in oral or head and neck squamous cell carcinoma 2: chromosomal aberrations. Oral Oncol 36: 311-327.

2. Vora HH, Shah NG, Patel DD, Trivedi TI, Chikhlikar PR (2003) Prognostic significance of biomarkers in squamous cell carcinoma of the tongue: multivariate analysis. J Surg Oncol 82: 34-50.

3. Jerjes W, Upile T, Petrie A, Riskalla A, Hamdoon Z, et al. (2010) Clinicopathological parameters, recurrence, locoregional and distant metastasis in 115 T1-T2 oral squamous cell carcinoma patients. Head Neck Oncol 20: 2-9.

4. Teixeira G, Antonangelo L, Kowalski L, Saldiva P, Ferraz A, et al. (1996) Argyrophilic nucleolar organizer regions staining is useful in predicting recurrence-free interval in oral tongue and floor of mouth squamous cell carcinoma. Am J Surg 172: 684-688.

5. Ginos MA, Page GP, Michalowicz BS, Patel KJ, Volker SE, et al. (2004) Identification of a gene expression signature associated with recurrent disease in squamous cell carcinoma of the head and neck. Cancer Res 64: 55-63.

6. Jekel JF, Elmore JG, Katz DL (1996) Understanding and reducing errors in clinical medicine. Jekel JF, Elmore JG, Katz DL (Eds), Epidemiology, biostatistics and preventive Medicine. Philadelphia: WB Saunders: 85-97.

7. Braakhuis BJ, Tabor MP, Leemans CR, van der Waal I, Snow GB, et al. (2002) Second primary tumors and field cancerization in oral and oropharyngeal cancer: molecular techniques provide new insights and definitions. Head Neck 24: 198-206.
8. Braakhuis BJ, Leemans CR, Brakenhoff RH (2004) A genetic progression model of oral cancer: current evidence and clinical implications. J Oral Patho Med 33: 317-322.

9. Carvalho AL, Magrin J, Kowalski LP (2003) Sites of recurrence in oral and oropharyngeal cancers according to the treatment approach. Oral Diseases 9: 112-118.

10. Huang TY, Hsu LP, Wen YH, Huang TT, Chou YF, et al. (2010) Predictors of locoregional recurrence in early stage oral cavity cancer with free surgical margins. Oral Oncol 46: 49-55.

11. de Aguiar AF Jr, Kowalski LP, de Almeida OP (2007) Clinicopathological and immunohistochemical evaluation of oral squamous cell carcinoma in patients with early local recurrence. Oral Oncol 43: 593-601.

12. Brennan JA, Mao L, Hruban RH, Boyle JO, Eby YJ, et al. (1995) Molecular assessment of histopathological staging in squamous-cell carcinoma of the head and neck. N Engl J Med 332: 429-435

13. Shin DM, Lee JS, Lippman SM, Lee JJ, Tu ZN, et al. (1996) p53 expressions: predicting recurrence and second primary tumors in head and neck squamous cell carcinoma. J Nat Cancer Inst 88: 519:529.

14. Silva SD, Agostini M, Nishimoto IN, Coletta RD, Alves FA, et al. (2004) Expression of fatty acid synthase, ErbB2 and $\mathrm{Ki}-67$ in head and neck squamous cell carcinoma. A clinicopathological study. A clinicopathological study. Oral Oncol 40: 688-696.

15. Ulanovski D, Stern Y, Roizman P, Shpitzer T, Popovtzer A, et al. (2004) Expression of EGFR and Cerb-B2 as prognostic factors in cancer of the tongue. Oral Oncol 40: 532-537.

16. Conacci-Sorrell M, Zhurinsky J, Ben-Ze'ev A (2002) The cadherin-catenin adhesion system in signaling and cancer. J Clin Invest 109: 987-991.

17. Chow V, Yuen AP, Lam KY, Tsao GS, Ho WK, et al. (2001) A comparative study of the clinicopathological significance of E-cadherin and catenins (alpha, beta, gamma) expression in the surgical management of oral tongue carcinoma. J Cancer Res Oncol 127: 59-63.

18. Kuhajda FP, Jenner K, Wood FD, Hennigar RA, Jacobs LB, et al. (1994) Fatty acid synthesis: a potential selective target for antineoplastic therapy. Proc Nat Acad Sci U S A 91: 6379-6383.

19. Kuhajda FP (2000) Fatty-acid synthase and human cancer: new perspectives on its role in tumor biology. Nutrition 16: 202-208.

20. Pizer ES, Lax SF, Kuhajda FP, Pasternack GR, Kurman RJ (1998) Fatty acid synthase expression in endometrial carcinoma: correlation with cell proliferation and hormone receptors. Cancer 83: 528-537.

21. Krontiras H, Roye GD, Beenken SE, Myers RB, Mayo MS, et al. (1999) Fatty acid synthase expression is increased in neoplastic lesions of the oral tongue. Head Neck 21: 325-329.

22. Scholzen T, Gerdes J (2000) The Ki-67 protein: from the known and the unknown. J Cell Phsiol 182: 311-322.

23. Kill R (1996) Localization of the Ki-67 antigen within the nucleous:Evidence for a fibrillarin-deficient region of the dense fibrillar component. J Cell Sci 109 1253-1263.

24. Petruzzelli GJ (2001) The biology of distant metastases in head and neck cancer. ORL J Otorhinolaryngol Relat Spec 63: 192-201. 